\title{
"Electricity Derivatives and the spot market in Italy. Mitigating market
}

$$
\text { power in the electricity market"*. }
$$

Valeria Termini, Advanced School of Public Administration and GME*

and

\section{Laura Cavallo, Department of Economic Affairs, Prime Minister's Office}

\begin{abstract}
The increased uncertainty regarding electricity prices caused by the liberalization of the sector and the launch of wholesale spot electricity markets has led to the development of financial derivatives both in regulated and over-the-counter markets. The ability of the spot market to stimulate the economic efficiency and competitiveness of the energy sector depends crucially on its efficiency and liquidity. However, as the theoretical analyses developed after the Californian crisis show, the concentration of spot-market transactions in the day-ahead market in a non-competitive industry exposes electricity prices to excessive peaks and volatility. This is due to their higher exposure to the exercise of market power by the dominant producer as well as to contingent events. This paper argues that introducing a regulated market for standardized derivatives, while giving consumers a strategic role in the market, would contribute to solving the trade-off between the liquidity of the market and the stability of the system. Some interesting policy implications emerge from the analysis.
\end{abstract}

JEL Classification: G18, L94, Q41, Q48

Keywords: Derivatives, Electricity, Market power, Hedging.

\footnotetext{
${ }^{*}$ The views presented here are not attributable to GME or to the Prime Minister's Office. The usual disclaimers apply. The authors thanks participant to the International Conference on: "Towards a European Market of Electricity: What Have We Learnt from Recent Lessons? Spot Market Design, Derivatives and Regulation”, Rome, 24-25 June 2002. A particular thank to R. Green, P. Joskow, E. Barone for useful comments and suggestions. The usual caveats apply.

* Valeria Termini, Scuola Superiore della Pubblica Amministrazione, Presidenza del Consiglio dei Ministri, e Gestore del Mercato Elettrico (GME), Roma, Italy Via Muggia 4, 00195 Roma, tel: +3906 80124530, fax: +39 06 3724165, E-mail: termini@sspa.rupa.it.

- Laura Cavallo, Presidenza del Consiglio dei Ministri, Via Barberini 38, 00187, Roma, Italy, tel:+39 06 42153417 fax: +39 0642153410 , e-mail: 1.cavallo@palazzochigi.it
} 


\section{Introduction}

The electricity spot market can play an important role in fostering the industry liberalization process. It can benefit both consumers and producers: the former profit from the price advantages arising from the transparency and competition promoted by the pool, which should allow them to purchase electricity on the "best terms"; the latter from efficient price signals, which help guide investment decisions towards an optimal allocation of capacity. Both benefit from the flexibility provided by the pool, since they can adjust their trading programs until the day before by carrying out trades on the "day-ahead" market.

Naturally, the fundamental condition for these expected benefits to be realized is a liquid pool - i.e. pool transactions must be attractive for operators used to long-term bilateral contracts. However, there are two obstacles to achieving adequate liquidity. First, since electricity is a non-storable good, its price is particularly exposed to fuel price volatility and to surges caused by temporary imbalances between the demand for and supply of electricity. The Pool's hourly auction mechanism increases price volatility and this is the first obstacle to overcome. Financial tools can be used to hedge against the volatility of electricity prices, but they point to the second problem affecting the liquidity of the Pool: the risk that the pricing of financial derivatives will strengthen the market power of the dominant operator.

This paper argues that a regulated market for standardized electricity financial derivatives offers an efficient solution to both problems and would thus foster the liberalization of the industry. Moreover, such a market would permit synergy between derivative and physical electricity transactions and enhance the liquidity of both markets without having to impose the concentration of transactions on the spot market.

In Italy, the liberalization program of the electricity industry, which was launched in compliance with Community guidelines by Legislative Decree 79/1999, includes the 
introduction of an electricity spot market. However, the concentration of trades on the Italian electricity spot market is not compulsory: the trading system is similar to Nord Pool. It is somewhere between the complete concentration of the English Pool, the Californian Pool and the new Australian market and a system based on bilateral contracts, such as that introduced by NETA in the UK. In addition to the centralized hourly auction market, where the system marginal price is determined, bilateral transactions are permitted provided they have been authorized by the regulatory authority. One of the problems of such a system is how to ensure market liquidity.

From this point of view, and referring to the Italian electricity market, in this paper we develop a model with which to investigate whether:

1. an electricity derivatives market can increase the liquidity of the spot market;

2. the expected benefits from a regulated derivatives market can be produced even in the presence of a dominant operator;

3. the demand side can play a role in the electricity market.

We argue that introducing a regulated electricity derivatives market and giving large electricity consumers an active role can help to increase the liquidity of both markets and influence the System Marginal Price, even in the presence of a dominant operator.

The paper is organized as follows. Section 2 describes the initial conditions of the electricity industry in Italy, as well as the main characteristics of the Italian spot market. Section 3 provides a summary of the theoretical literature dealing with the impact of electricity derivatives on the spot market. Section 4 develops a theoretical model of the behavior of electricity consumers and generators in the presence of a futures market. Section 5 concludes and discusses policy implications, caveats and institutional solutions. 


\section{Electricity markets in Europe and the initial conditions of the Italian spot market}

Prior to Directive 96/92/EC establishing guidelines for the liberalization of the electricity sector in Europe, only two pioneers had introduced a centralized pool for electricity transactions: England and Wales launched the Pool in 1990 as a first step in a liberalization program paving the way to the privatization of the Central Electricity Generating Board CEGB,, the state-owned vertically integrated statutory monopoly since 1948; Norway introduced Nord Pool in 1993 and later involved the other Scandinavian countries, thus combining liberalization with cross-country market integration. The late 1990's and the turn of the millennium saw a rush to establish new pools around Europe (summarized in Chart 1), irrespective of market conditions in the national electricity industries.

Italy responded to the 1996 European Directive with Legislative Decree 79/1999, which, reflecting the guidelines calling for the unbundling of generation, transmission and distribution functions, shaped the future development of the sector and provided for competition in production and supply. On the production side, deadlines were set for reducing Enel's monopoly share of electricity generating capacity: from $77.8 \%$ in 1999 to a maximum of 50\% in 2003 (Enel, the state-owned monopoly producer since 1964, was required to divest at least $15 \mathrm{GW}$ of generating capacity by 2002). On the demand side, large customers (consuming more than $30 \mathrm{GWh}$ per year in 1999 and more than $9 \mathrm{GWh}$ per year today, with associations of buyers also being allowed) were considered "eligible clients", free to choose from whom to buy, while small consumers were to remain the captive market of local distributors. Finally, as regards high-voltage transmission, the national grid was to be franchised to a state-owned company, which would not own the grid but be responsible for dispatching and running the transmission system.

New institutions were created to permit implementation of this program: the Electricity and Gas Authority (EGA) in 1997 and three new Treasury-owned companies: the 
national grid operator (GRTN - Gestore della Rete di Trasmissione Nazionale) in 1999, the single buyer (AU - Acquirente Unico) in 1999 and, lastly, the electricity market operator (GME - Gestore del Mercato Elettrico) in 2000.

The three companies were given different objectives. Security and the physical stability of the system is entrusted to the national grid operator, while short-run and long-run efficiency, to be reached through price signals, is the objective of the electricity market operator. The latter's market rules were approved in May 2001 by the Ministry of Productive Activities after consulting the Electricity and Gas Authority. It is to run five different markets (Chart 2): two energy markets (i.e. the day-ahead energy market and the adjustment market) and three markets for the procurement of resources for the dispatching service (i.e. the congestion management, reserve and balancing markets). Generators' offers will be selected in the hourly auction of the day-ahead market according to economic order, after a check of network compatibility by the national grid operator, which examines whether the unconstrained schedule of supply and demand faces transmission constraints. The accepted demand and supply offers will then determine the Pool price at the margin - i.e. the System Marginal Price (SMP), which will be the electricity price for all the generating plants called upon to produce in that hour. Should network congestion arise, the country would be divided into up to 5 zones, as shown in Chart 3; accordingly, different zonal prices should give producers price signals for efficiently allocating new generating plants, thus promoting longterm efficiency. A transitional solution is envisaged for large consumers buying electricity in the pool: a uniform System Marginal Price for buyers, should ensure a smooth two-year "adjustment period", even in the presence of different zonal prices for producers.

Pool transactions are not compulsory, bilateral contracts are admitted, subject to authorization by the Electricity and Gas Authority, according to criteria still to be defined.

This system means a dramatic change for Italian operators used to dealing with the high but stable costs involved in a system of tariffs and long-term bilateral contracts with 
Enel. Furthermore, a similar costly stability was embodied in the local distribution networks run by municipal utilities since the beginning of the century. This helps to explain why the new system is still on the way towards completion. Moreover, the structure of the market is still far from ensuring competitive conditions for market bids.

The following data outline the structure of the Italian electricity industry. Chart 4 shows the size of the market and the breakdown of supply between imports and internal production. Chart 5 illustrates the capacity balance at the peak in 2001 and import capacity, in order reveal the reserve capacity of the system. A potential shortage of capacity emerges from these data. Charts 6,7 and 8 illustrate the structure of the industry: the first two show the concentration of production in 2001 and the breakdown of demand by eligible customers. Chart 8 compares the composition of electricity generation by source in Italy with that in the major European countries. It reveals two critical points for the Italian electricity industry deriving from the large proportion of thermal power used (about $76 \%$ ): the high cost of generating electricity due to oil-related inputs and the high price volatility which producers have to face (Chart 9). The entities working in the new market structure are depicted in Chart 10; a substantial expansion in traders is expected.

This increases the need for a regulated market in electricity derivatives in addition to the spot wholesale market. Providing market players with a safe market for sharing price risk is essential if the new system is to be successfully implemented. This conclusion is supported by international experience. The Scandinavian countries are a good example of how physical and financial electricity markets can develop gradually and synergically (Chart 11). California, on the contrary, warns us, among other things, of the risk of bankruptcy facing distribution companies that are not allowed to adopt a hedging strategy by strict regulatory rules. 


\section{Competition, stability and financial derivatives in electricity spot markets: the economic theory.}

The Californian crisis has been a catalyst for reflection on liberalization. The literature shows that the physical characteristics of electricity and the typically non-competitive structure of the market make spot-market prices very volatile and susceptible to market power problems. One conclusion of the debate (Joskow, 2001; Wolak, 2000; Bushnell, 2001; et al) is that in a non-competitive industry most of the demand for electricity should be met by longterm contracts, and only a small part should be channeled to the spot market and be fully exposed to price volatility. However, a necessary condition for a liberalization program's success is the efficiency of the spot market and this cannot be guaranteed when it handles only a small fraction of transactions. An alternative way of protecting operators from price volatility is to ensure that they can hedge their spot-market positions. Since the early 1990s an interesting body of literature has developed on this issue and on the impact of financial derivatives on spot-market equilibrium

There are two strands to this literature. The first dating from the introduction of the Pool in England and Wales and Nord Pool in Scandinavia focuses on UK experience and mainly deals with the ability of derivatives contracts to mitigate market power in monopolistic/oligopolistic market structures (Green and Newbery, 1992; Allaz \& Vila, 1993; Powell, 1993; Green, 1999). The second, more recent strand focuses on US experience and mainly deals with the stability of the system and the contribution of derivatives to the stability of the wholesale electricity spot market .

The first strand demonstrates that in the presence of hedging contracts, dominant operators lose their incentive to exercise market power over spot-market prices. The behavior of electricity generators, facing an extremely inelastic demand, is analyzed by modeling the spot-market equilibrium either with supply functions (Green and Newbery, 1992; Newbery, 
1995, 1998) ${ }^{1}$ or with multi-unit simultaneous auctions (von der Fehr and Harbord, 1992). In a simultaneous auction system the dominant generator can exercise market power either by reducing supply or, given the system marginal price $(\mathrm{SMP})^{2}$ mechanism, by differentiating between the bid prices of different generating units in accordance with a profit-maximizing strategy. In fact, with the SMP mechanism, all dispatched units are paid at the market clearing price, which is equal to the price bid by the most expensive unit among those selected to supply electricity. The dominant operator thus has an incentive to offer a price higher than the marginal cost for some units. The risk of losing market share - since these units will not be called upon to supply electricity — will be more than compensated by the higher profits that can be obtained from the other units called into operation (Green e Newbery 1992).

The main finding of this strand of the literature is that dominant operators who hedge their positions on the spot market will lose the incentive to raise prices above marginal costs. In fact, if generators sell their output forward, the extra-profits obtainable on the spot market are offset by the losses on the derivatives market. The spot price affects their net profits only for the fraction of electricity not covered by derivatives contracts. Furthermore, the hedging strategy allows generators to practice an aggressive price policy on the spot market and to counter the threat of new entrants by reducing the price of electricity. Therefore, the existence of financial futures contracts implies a greater supply on the spot market and pushes prices closer to marginal cost. Allaz and Vila (1993) show that sequential markets may lead to even less market power than one-shot markets. Wolfram (1999) indicates the existence of financial

\footnotetext{
${ }^{1}$ The supply function used is the one proposed by Klemperer and Meyer,1989. Different degrees of competition can be modeled using conjectural specifications (Bertrand or Cournot conjectures). The Cournot specification lies at one extreme of the supply function models.

${ }^{2}$ The units called upon to supply electricity on the spot market are selected on the basis of the prices at which they are willing to supply electricity, ranked by the auctioneer to construct a market supply curve, consistently with the transmission network constraints evidenced by the national transmission network operator.
} 
contracts as one of the possible explanations for observed price-cost markups not being as high as most theoretical models would predict.

Another role of financial derivatives is their contribution to promoting competition by making the generating market more contestable. Newbery (1998) shows that with limited capacity, if potential entrants could compete with the incumbents in the contract market, entrants would be covered from the post-entry price risk. Furthermore, Green (1999) indicates that "Contracts for Differences" or CfDs guarantee generators a secure flow of income from the output they expect to sell in the future, and hedge them against the volatility of power input prices. The possibility of using CfDs permits both future incomes and future costs to be insured, providing new entrants with a solid financial structure that facilitates the financing of investments in new generating units.

Alongside these positive aspects of financial derivatives, i.e. their ability to mitigate market power and promote competition among producers, the literature also reveals some negative aspects. Newbery (1998) indicates that if the industry has enough total capacity, the incumbents can easily deter entry, by using contract cover as an instrument for dumping. Similarly, Gans, Price and Woods (1998) demonstrate that in a dynamic setting, by lowering electricity prices and hence the profits of individual generators, CfDs could make entry unattractive, with the risk of having higher prices in the long run. Furthermore, Green (1999) shows that generators could set a price of financial contracts higher than the expected marginal cost, thereby earning the risk premium that consumers are willing to pay to cover against the volatility of the hourly or half-hourly price.

All these theoretical contributions concentrate on the pricing strategy of the dominant operator as the determinant of the price of electricity in a centralized market. They find that the effects of derivatives on the spot-market price depend crucially on the level of hedging by the dominant generator. In the case of full contracting the price would be equal to the 
marginal cost. This conclusion gives a critical role to the quantity of electricity that the generator is willing to sell forward.

Both theoretical arguments and empirical evidence support the hypothesis that generators hedge most of their output through derivatives contracts. According to Powell (1993) and Green (1999) the fact that consumers tend to be more risk averse than generators gives the latter an incentive to sell derivatives contracts in pursuit of the risk premium. That conviction has led to the more opaque mechanism of bilateral contracts and to NETA. A second argument supporting the high proportion of hedging by the dominant operator (Green, 1999 ) is that generators can use derivatives as a commitment device to prevent new entries or regulatory intervention. In an oligopoly, firms can sign derivatives contracts to increase their market share. The empirical evidence supports the hypothesis that generators cover most of their output in the derivatives market (Green, 1999, gives evidence regarding the electricity supply industry in England and Wales).

The second, more recent strand of this literature, focusing on US experience, analyses the effect of financial derivatives contracts on the stability of the system under the hypothesis that all electricity transactions pass through the spot market. The experience of California, where distributors were prevented from hedging on the financial market by a strict regulatory framework, supports the main conclusions of the theoretical literature summarized above. Wolak (2000), Joskow (2001) and Green (2001) indicate that the use of derivatives would have helped to curb price surges and allowed distribution companies to hedge against the volatility of wholesale prices.

The studies of the Californian experience with a centralized electricity spot market reveal two additional critical points. First, the absence of a strategic role for the buyer, as pointed out, among others, by Bushnell (2001): all the theoretical studies on the topic concentrate on the behavior of generators. The main reason why demand is not given an active role is its pronounced price inelasticity. The large number of buyers (in particular small 
buyers) does not facilitate strategic behaviours.. The presence of asymmetric regulation (as in the Californian case) may further insulate consumers from price signals. ${ }^{3}$ Second, the risk implicit in concentrating a large volume of transactions on the day-ahead market in noncompetitive situations, as evidenced by Joskow (2001). The need for imminent consumption heightens the market power of the dominant operator: in this situation, any irregularity in the quantity of electricity offered on the market can lead to price surges, with highly destabilizing effects on the system. Joskow's proposal is to ensure that a large fraction of retail transactions be met by long-term bilateral contracts, and that only a small fraction be fully exposed to the price volatility of the spot market. Bilateral contracts should increase the stability of the system by fixing the long-run price of electricity. However, such contracts are not transparent and, on their own,do not give market operators the same flexibility of spot-market transactions, where both generators and consumers can modify their decisions to sell or to buy electricity until the "day-ahead". There thus seems to be a hard-to-resolve trade-off between the liquidity of the spot market and the stability of the system. This gives rise to a vicious circle, since liquidity is a necessary condition for the efficiency of the spot market. This is confirmed by international experiences with liberalization: one of the main obstacles to the full development of electricity spot markets is their lack of liquidity.

The model developed in this paper focuses on this issue. It examines whether an electricity futures market offers a solution to the liquidity-stability trade-off in noncompetitive situations. The results of the model suggest that a regulated market of standardized instruments on the electricity price, together with regulations permitting

\footnotetext{
${ }^{3}$ In the presence of asymmetric regulation, the distributors buy electricity on the spot market at wholesale market prices and sell it to consumers at regulated prices. In most countries, as California, regulated prices are fixed for a period of about four years (in some cases, as in the UK, the formula may include a generating cost pass-through). If retail prices are fixed prices, consumers are not exposed to the risk of market price volatility, but at the same time they do not receive information on the behavior of market prices.
} 
consumers to play an active role in the market, can enhance the liquidity of the spot market and reduce the instability of the system. From this analysis some important policy implications also arise, allowing regulators to play a stabilizing role that does not interfere directly with the spot pricing mechanism in the transition towards complete liberalization.

\section{The model}

\subsection{The role of demand in spot-market transactions}

In the first part of the analysis we model the behavior of electricity consumers who can buy electricity on the spot market or through bilateral contracts. This situation reflects the initial conditions of the Italian market.

As discussed above, most of the literature on electricity spot markets analyses the supply side of the market, taking demand as given. In this paper, by allowing electricity consumers to choose the fractions of electricity they want to buy on the spot market and through bilateral contracts, we give an active role to demand. In order to examine the effect of a futures market on electricity buyers' behavior, we compare consumers' optimizing choices in the absence and in the presence of a futures market.

Consumers are assumed to be risk averse, their objective function being modeled by a negative exponential utility function:

$U(W)=-\exp (-\rho W)$

where $\rho$ is the risk-aversion coefficient and $\mathrm{W}$ is consumers' welfare. In this case $\mathrm{W}$ is negative as it corresponds to the total cost of buying electricity. 
Assuming that consumers' welfare $\mathrm{W}$ has a normal distribution with mean $\mathrm{E}(\mathrm{W})$ and variance $\operatorname{Var}(W)$, maximizing the expected utility $E[U(W)]$ is equivalent to maximizing the following objective function: ${ }^{4}$

$$
E(W)-\frac{\rho}{2} \operatorname{Var}(W)
$$

Consumers' total cost (expressed as negative wealth) is given by the sum of the cost of electricity bought on the spot market plus the cost of that bought through bilateral contracts:

$$
W=-q\left[s p_{s}+(1-s)\left(p_{B C}+k_{B C}{ }^{C}\right)\right]
$$

where $\mathrm{q}$ is the total demand for electricity, $\mathrm{s}$ is the fraction of electricity purchased on the spot market, $\mathrm{p}_{\mathrm{S}}$ is the spot-market price, $\mathrm{p}_{\mathrm{BC}}$ is the price of bilateral contracts, assumed to be exogenous, $k_{B C}{ }^{C}$ are the costs incurred by consumers in buying bilateral contracts, assumed to be proportional to the quantity of electricity bought. These costs include not only the fees (which are at least partly offset by the spot-market fees implicit in the model) but also the costs represented by the lower flexibility of bilateral contracts compared to the spot market (these costs have to be considered net of any advantages obtainable, in particular cases, with bilateral contracts).

Maximizing the utility function with respect to s, and rewriting the relevant first order condition with respect to the optimal share of demand that passes through the spot market $\mathrm{s}_{\mathrm{c}} * \mathrm{q}$, we obtain:

\footnotetext{
${ }^{4}$ In this case, we have assumed the negative exponential form for the utility function merely for the sake of simplicity. Any utility function can be approximated with the mean-variance expression and our model does not depend on the particular utility function chosen.
} 


$$
\mathrm{s}_{\mathrm{c}} * \mathrm{q}=\frac{p_{B C}-E\left(p_{s}\right)+k_{B C}^{C}}{\rho \operatorname{Var}\left(p_{s}\right)}
$$

That may be written in the standard form:

$\mathrm{q} q_{s}=A-b p_{s}$

where:

$\mathrm{q}_{\mathrm{s}}$ is the share of total demand that passes trough the spot market,

$$
\begin{aligned}
& \mathrm{A}=\frac{p_{B C}+k_{B C}^{C}}{\rho \operatorname{Var}\left(p_{s}\right)} \text { and } \\
& b=\frac{1}{\rho \operatorname{Var}\left(p_{s}\right)}
\end{aligned}
$$

As expected, this quantity depends on the difference between the cost of buying electricity on the spot market rather than through bilateral contracts, to an extent that varies with the degree of risk aversion and the volatility of the spot price. Note that consumers would be willing to pay a slightly higher price on the spot market than for bilateral contracts in order to exploit the greater flexibility offered by spot-market transactions. Equation 4 suggests that futures contracts may have a positive impact on the liquidity of the spot market by making it possible to hedge against the risk of price fluctuations. This hypothesis is further examined by modeling consumers' behavior in the presence of a futures market. The wealth of a consumer hedging his spot-market position with futures contracts is:

$W^{\prime}=-q\left[s p_{s}+(1-s)\left(p_{B C}+k_{B C}{ }^{C}\right)\right]+x\left(F_{1}-F_{0}\right)$ 
where $\mathrm{x}$ is the quantity of electricity hedged assuming long positions in futures contracts and $F_{1}$ and $F_{0}$ are, respectively, the futures prices at $t_{1}$ and $t_{0}$. The buyer will obtain a positive result from the futures market if $\left(\mathrm{F}_{1}-\mathrm{F}_{0}\right)>0$.

In the presence of a futures market, a buyer's optimal choice for the quantity of electricity to buy on the spot market $s_{c}{ }^{*} q$ will be:

$$
s_{c}{ }^{*} q=\frac{p_{B C}-E\left(p_{s}\right)+k_{B C}^{C}}{\rho\left[\operatorname{Var}\left(p_{s}\right)\right]}+x \frac{\operatorname{Cov}\left(p_{s}, F_{1}\right)}{\left[\operatorname{Var}\left(p_{s}\right)\right]}
$$

The first part of this expression is equal to Equation 4, obtained in the absence of a futures market. The difference lies in the second term. Under the standard assumption of a positive correlation between spot and futures prices, the second term is always positive.

It follows that:

Proposition I - If a risk-averse consumer is allowed to decide whether to buy electricity on the spot market or through bilateral contracts, the presence of a futures market increases the fraction of demand that passes through the spot market.

This proposition points to a positive role for consumers' choices in the market.

As a corollary, the size of the futures market's impact on the optimal choice of $\mathrm{s}$ depends on the correlation between the spot price and the futures price. The higher this correlation, the greater will be the ability of a futures market to increase spot-market liquidity.

If we simultaneously determine the first-order condition which identifies the buyers' choice of $x$, we obtain:

$x=\frac{E\left(F_{1}\right)-F_{0}+}{\rho \operatorname{Var}\left(F_{1}\right)} \frac{\operatorname{sqov}\left(p_{s}, F_{1}\right)}{\operatorname{Var}\left(F_{1}\right)}$ 
The demand for futures contracts also depends positively on the correlation between the spot market and the futures market. A high correlation has a positive impact not only on the liquidity of the spot-market but also on that of the derivatives market, with synergic effects between the spot and futures markets.

\subsection{The electricity spot market: the generator's behavior}

The second step of the analysis is to model the behavior of a monopoly generator, consistently with the Italian case. The hypothesis of a monopoly generator can be generalized to the case of two generators acting cooperatively. In that case we can model the generator as a quantity or price setter. Let us assume a risk-neutral generator ${ }^{5}$ with a generic cost function $C(q)$ and marginal costs $c(q)$. Both buyers and the generator can cover their spot-market positions through futures contracts.

The objective function for a generator who sells a fraction $s$ of its total capacity $q$ through the spot market and the residual $(1-s) q$ through bilateral contracts, and opens a short position on the futures market to cover its positions on the spot market can be written as:

$$
\Pi=p_{S} s q+\left(p_{B C^{-}} k_{B C}^{G}\right)(1-s) q-x\left(F_{1}-F_{0}\right)-c(q)
$$

where $p_{S}$ is the spot-market price, $p_{B C}$ is the price of bilateral contracts, assumed to be exogenous, $x$ is the quantity of output covered by futures contracts and $F_{1}$ and $F_{0}$ are,

\footnotetext{
${ }^{5}$ The hypothesis of risk-averse generators leads to the same conclusions and is provided in an Appendix available from the authors upon request.
} 
respectively, the futures prices at $t_{1}$ and $t_{0}, k_{B C}{ }^{G}$ are the costs the generator faces selling electricity through bilateral contracts. These costs reflect not only the lower flexibility of bilateral contracts (which tends to offset the analogous costs faced by the consumer and would not affect the equilibrium price) but also the costs of being subject to regulatory control (since bilateral contracts have to be authorized by the regulator). These costs are assumed to be proportional to the quantity sold through bilateral contracts. They can also be interpreted as inversely correlated with the quantity sold on the spot market, as they reduce the generator's incentive to reduce the quantity of electricity sold on the spot market to drive up spot prices. Differently from most of the literature on this topic, where spot-market positions are hedged via "Contracts for Differences" or CfDs, here we assume the existence of a regulated futures market. This market is characterized by standardized contracts and by the presence of a clearing house which guarantees the participants from counterparty risk. Although using a futures market rather than CfDs does not substantially change the analytical structure and results of the model, the impact on the liquidity of the market can be significant. One of the reason is thatStandardized futures contracts may be attractive also for non-electricity traders and are generally characterized by a higher liquidity of the market..

As in Allaz \& Vila, 1986, the demand that passes through the spot market, with additive and normally distributed error, has the following form:

\footnotetext{
${ }^{6}$ In a commodities futures market, the relationship between the futures price $\mathrm{F}(\mathrm{t}, \mathrm{T})$ of a contract with maturity $\mathrm{T}$ and the spot price at time $t \mathrm{~S}(\mathrm{t})$ which ensures that there are no arbitrage opportunities is: $F(t, T)=S(t) e^{(t-y)(T-t)}$ where $\mathrm{r}$ is the risk-free rate and $\mathrm{y}$ the convenience yield given by the difference between the positive return from owning the commodity and the cost of storage. In our case it would be: $F_{1}=p_{s} e^{(r-y)(t 1-t 0)}$. As observed by Geman (2001), this relationship does not hold perfectly in the case of electricity and in general of power, because of non-storability, which also invalidates the non-arbitrage argument. For our purposes however, the exact
} 


$$
p_{S}=A-b s q+\varepsilon \quad \text { where } \varepsilon \sim \mathrm{N}\left(0, \sigma^{2}\right) \quad(7)
$$

The A and b parameters have been derived in Section 4.1 and indicated by equation 4').

Assuming the following relationship between the spot and futures prices at time $\mathrm{t}$ :

$$
F_{t, T}=p_{s t, B} B(r, \tau)
$$

where $\tau=T$ - $t$ is the time to maturity of the futures contract,

and

$\mathrm{B}(\mathrm{r}, \mathrm{t})$ is the positive relation between the spot and the futures price, expressed as a function of $\mathrm{r}$, the market risk-free rate, and $\tau^{7}$

and replacing the expected spot price and futures price at time 1 , the profit of the generator will be:

$$
\Pi=(A-b s q) s q+\left(p_{B C}-k_{B C}^{G}\right)(1-s) q-x\left[(A-b s q) B(r, \tau)-F_{0}\right]-c(q)
$$

Differentiating the generators' profit with respect to s we obtain:

relationship between the spot and the futures price is not essential. The only necessary assumption for our results to be valid is that the relationship be positive. More generally, we assume that $F_{1}=p_{s} B(r, \tau)$.

${ }^{7}$ There is an intense debate on what is the appropriate function that describes the relationship between the futures and the spot price for the electricity market.. As observed by Geman (2001), the relationship generally assumed to describe this relationship for the commodities market (the usual form is: $F(t, T)=S(t) e^{(t-y)(T-t)}$ where $r$ is the risk-free rate and y the convenience yield given by the difference between the positive return from owning the commodity and the cost of storage s relationship) does not hold perfectly in the case of electricity and in general of power, because of non-storability, which also invalidates the non-arbitrage argument. For our purposes however, the exact relationship between the spot and the futures price is not essential. The only necessary assumption for our results to be valid is that relationship to be positive. We than decided to indicate this relationship with the term: $\mathrm{B}(\mathrm{r}, \tau)$. 


$$
\frac{\Delta \Pi}{\Delta s}=(A-b s q) q-\left(p_{B C}-\mathrm{k}_{\mathrm{BC}}^{\mathrm{G}}\right) q-b s q^{2}+b B(r, \tau) x q
$$

Given q, the total quantity of output produced by the generator, the expression which represents the profit-maximizing output offered on the spot market as a function of the expected spot price $\mathrm{Ep}_{\mathrm{s}}$ is:

$$
s_{G}^{*} q=\frac{1}{b}\left(E p_{s}-p_{B C}+k_{B C}^{G}\right)+x B(r, \tau)
$$

This result has the following implications:

Proposition II - If a generator with a generic cost function offers a quantity of electricity on the futures market close to the amount sold on the spot market, the spot price of electricity will be close to the price of bilateral contracts. The existence of opportunity costs for the generator to sell through bilateral contracts keeps the spot price slightly lower than the price of bilateral contracts.

As in Powell (1993) and Green (1999), the optimal share of electricity sold on the spot market is a positive function of $x$, the quantity of futures contracts that the generator is willing to sell to hedge the quantity $s q$ sold on the spot market. Differently from that of Powell (1993) and Green, our result is based on the assumption that for a given quantity of electricity offered by the generator, not all trades pass through the spot market but only a fraction $s$; it follows that $s q$ is not the total quantity of transactions but only the quantity traded on the spot market. Consequently, this quantity does not depend on marginal costs or on particular assumptions regarding the form of the cost function. 
Note that, in accordance with Proposition II, if the price of bilateral contracts net of the cost $k$ were equal to the marginal cost, the conclusion of the model would be analogous to that of Powell (1933), Green (1999), et al. in the case of all transactions passing through the spot market.

The implication of Proposition II is that, in the presence of a futures market and of a market for bilateral contracts, the generator would not drive the spot price above the price of bilateral contracts. In fact, as suggested by the literature on the role of financial contracts, the generator expects that any profit obtainable on the spot market by driving the price up will be offset by a loss on the futures market, and prefers to adopt a more aggressive strategy in the spot market. On the other hand, the presence of strategic consumers will deter the generator from driving the spot-market price above the price of bilateral contracts. The risk that strategic consumers may decide to purchase electricity through bilateral contracts is an incentive to keep spot prices low enough (below a "decency" ceiling) to prevent regulatory intervention.

\section{Concluding comments: policy implications and market design}

The model results have several policy implications and yield some interesting suggestions about the design of competitive electricity markets in the transition towards complete liberalization. The first implication (Proposition I) regards the dilemma: compulsory pool or consumers' choice. Most spot markets have imposed the concentration of transactions to ensure market liquidity. This paper shows that if consumers are given a strategic role, and can decide whether to buy electricity on the spot market or through bilateral contracts, the existence of futures contracts can contribute to market liquidity even without a 
formal concentration obligation. This result supports the decision of the Italian regulator not to impose the concentration of transactions on the electricity spot market provided the launch of the wholesale spot market is accompanied by that of a futures market.

This result has one further policy implication: if consumers are allowed to decide whether to buy on the spot market or through bilateral contracts, the generators and the distributors cannot be allowed to refuse to sign bilateral contracts. Allowing consumers to choose increases the price elasticity of demand, thus further reducing generators' incentive to exercise market power.

Since the effect of a futures market on liquidity depends on the correlation between spot and futures prices, electricity index prices have to be highly representative of spot-market behavior. Liquidity problems may appear to be transferred from the spot market to the futures market. However, our results suggest that a high correlation between spot and futures prices also has positive effects on the liquidity of futures markets, with synergic effects between spot and futures transactions.

Other interesting policy implications emerge from Proposition II. This indicates that if generators hedge their spot-market supply, the prices of spot and bilateral contracts tend to converge. It follows that there would be no need to limit the fraction of demand that passes through the spot market (as suggested by Joskow, 2001 et. al.) in order to mitigate the effects of market power on spot prices and ensure the stability of the system. The advantages of this result, in terms of spot-market liquidity and efficiency, are evident.

Furthermore, this result suggests that the regulator would be able to mitigate market power by acting on the price of bilateral contracts. Regulatory intervention is needed, at least in the transition towards liberalization. However, in contrast with the regulatory mechanism used in other countries (capping market prices), this form of intervention has a limited and indirect impact on market mechanisms. Moreover, regulatory intervention on the prices of bilateral contracts is triggered only when spot-market prices are not competitive and 
consumers choose to sign bilateral contracts. Otherwise, the regulatory intervention would not be operating, and the possibility for a regulatory intervention would only act as a disciplining device. In the Italian case, where bilateral contracts have to be authorized, these policy implications can give some important indications as to the conditions the electricity seller should meet in order to receive authorization. For example, the price of bilateral contracts should be competitive and lower than a cap reflecting marginal plant costs. Generators should have to offer bilateral contracts with the same characteristics to all consumers in order to ensure that every buyer receives the same treatment.

As in Powell (1993), Green(1999) and others, the attractive results of this paper depend crucially on the assumption that generators and consumers are willing to hedge their spot-market positions (the best results are obtained when generators fully hedge their positions). As shown in Section 3, many arguments are used to support the hypothesis that generators hedge most of their output through derivatives contracts. Here, the increase in the spot-market demand price-elasticity produced by giving a strategic role to demand and generators' desire to prevent regulatory intervention by committing themselves to keeping prices low would be an additional incentive for them to sell derivatives contracts (Wolak, 2000). A final suggestion of this study is that a regulated market for financial derivatives should be introduced, in addition to OTC transactions. In a regulated market the financial authority oversees transactions and the clearing house guarantees participants from counterparty risk, thereby reducing the risk of systemic crises. Furthermore, standardized futures contracts may attract non-electricity traders to the market. 


\section{Acknowledgements}

The views presented here are not necessarily attributable to the GME or to the Government.

The authors thanks participants to the International conference "Towards an European Market of Electricity" for useful comments and suggestions. In particular, the authors wish to thank Paul Joskow and Emilio Barone for interesting insights. Any remaining errors are solely the responsibility of the authors. 


\section{References}

Allaz, B. and J. L. Vila, 1986, Futures Markets Improve Competition, Princeton University, Working Paper.

Allaz, B. and J. L. Vila, 1993, Cournot Competition, Futures Markets and Efficiency, Journal of Economic Theory, vol. 59, no. 1, pp. 1-16.

Gans J. S., D. Price and K. Woods, 1998, Contracts and Electricity Pool Prices, Australian Journal of Management, vol. 23, no. 1.

Geman, H., 2001, Spot and Derivatives Trading in Deregulated European Electricity Markets, Economies et societes, vol. 35, nos. 1-2, pp. 263-80.

Green, R.J, and D.M.Newbery,1992, Competition in the British Electricity Spot Market, Journal of Political Economy vol. 100 no 5, pp. 929-53

Green, R.J., 1999, The Electricity Contract Market in England and Wales, Journal of Industrial Economics, vol. XLVII, no 1, pp. 107-124

Hogan, 2001, Electricity market restructuring: reforms of reforms, mimeo, Center for Business and Government, Harvard University.

Joskow, P., 2001, California’s Electricity Crisis, NBER Working Paper no. 8442

Klemperer, Paul D. and Meyer, Margaret A., 1989, Supply Function Equilibria in Oligopoly under Uncertainty, Econometrica, 57 (6, 1243-1277.

Newbery, 1998, Competition, contracts, and entry in the electricity spot market, Rand Journal of Economics, vol. 29, no. 4, pp. 726-749.

Newbery, David. M., 1995, Power Markets and Market Power, The Energy Journal, 16(3), 39-66.

Newbery, David. M., 2000, Privatization, Restructuring and Regulation of Network Utilities, (The Walras-Pareto Lectures, 1995, MIT Press, 2000, ISBN 0-262-14068-3 pp. $466+x v i$ 
Powell, Andrew, 1993, Trading Forward in an Imperfect Market: The Case of Electricity in Britain, The Economic Journal, 103, 444-453.

von der Fehr, N. H. M. and D. Harbord, 1993, Spot Market Competition in the UK Electricity Industry, The Economic Journal, 103, 531-546.

von der Fehr, N. H. M. and D. Harbord, 1993, Spot Market Competition in the UK Electricity Industry, The Economic Journal, 103, 531-546.

Wolak, 2000, An Empirical Analysis of the Impact of Hedge Contracts on Bidding Behavior in a Competitive Electricity Market, mimeo, Department of Economics, Stanford University.

Wolfram, Catherine D., 1999, Measuring Duopoly Power in the British Electricity Spot Market, The American Economic Review, vol. 89 no. 4. 


\section{European Electricity Markets}

\section{Electricity Pools:}

- Electricity Pool (England) 1990

- Nord Pool (Scandinavian Countries) *

- Norway 1993

- Sweden 1996

- Finland 1998

- Denmark 2000

- OMEL (Spain) 1998

- APX (Netherlands) 1999

- NETA (England) 2001*

- EEX Frankfurt (Germany) 2000

- LPX Leipzig (Germany) 2000 *

- PPE Warsaw (Poland) 2000

- Opcom (Romania) 2001

- Powernext (France) 2001

- Borzen (Slovenia) 2002

- EXAA (Austria) 2002

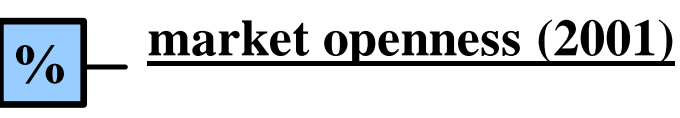

* Electricity Spot Markets on which financial derivatives on the electricity price are traded
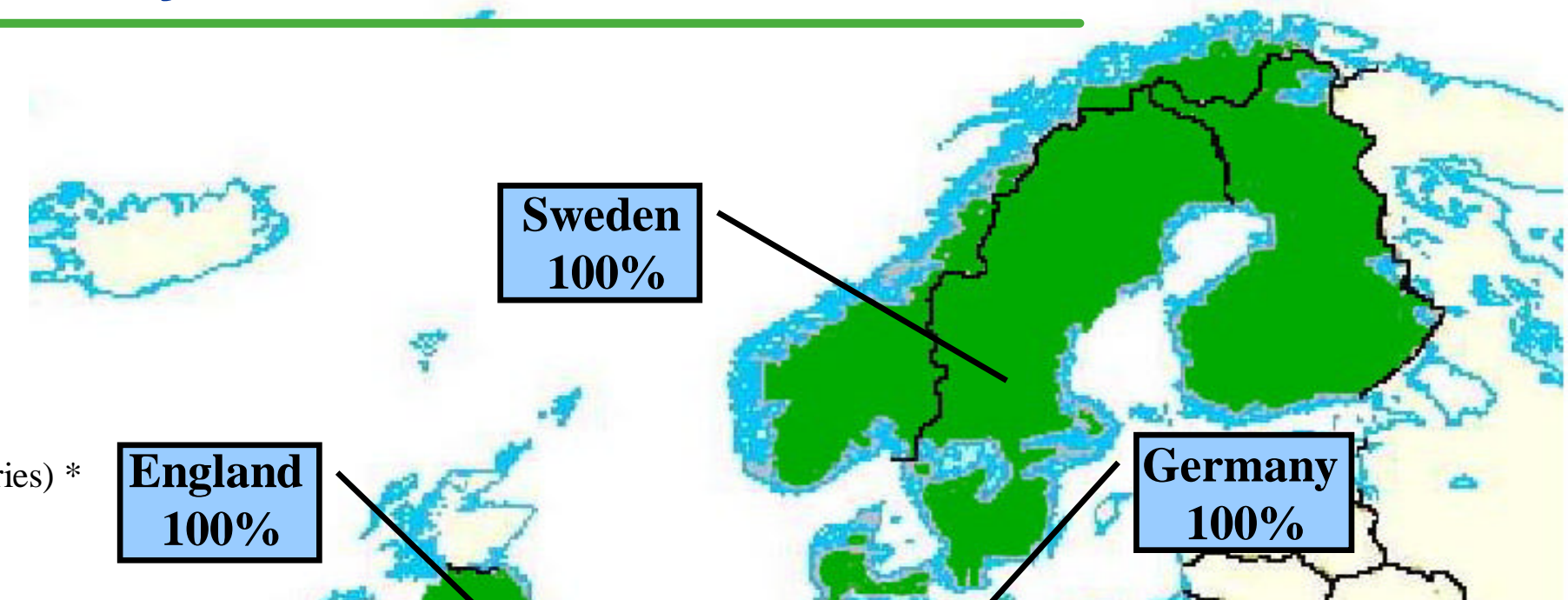

.

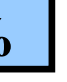
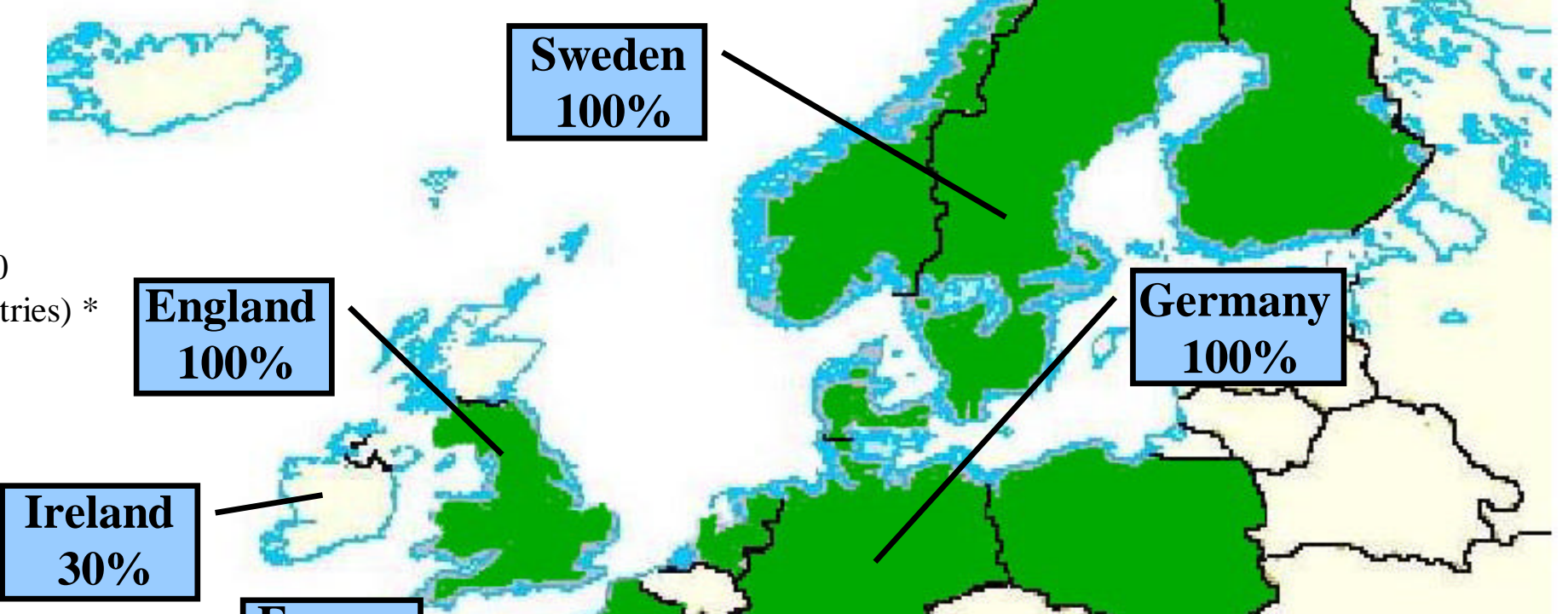

*

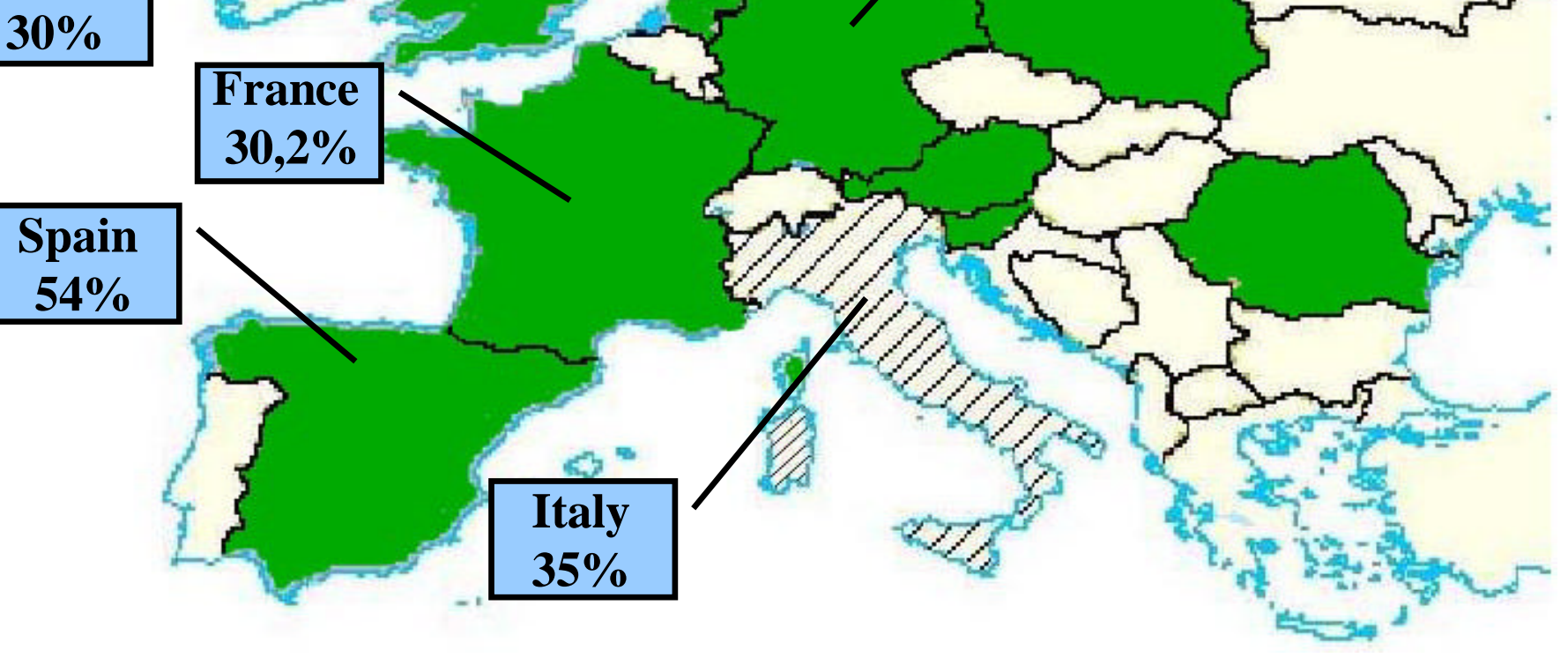

Source: E.C.

[Chart 1] 


\section{The Electricity Market in Italy}

\section{Market Participants}

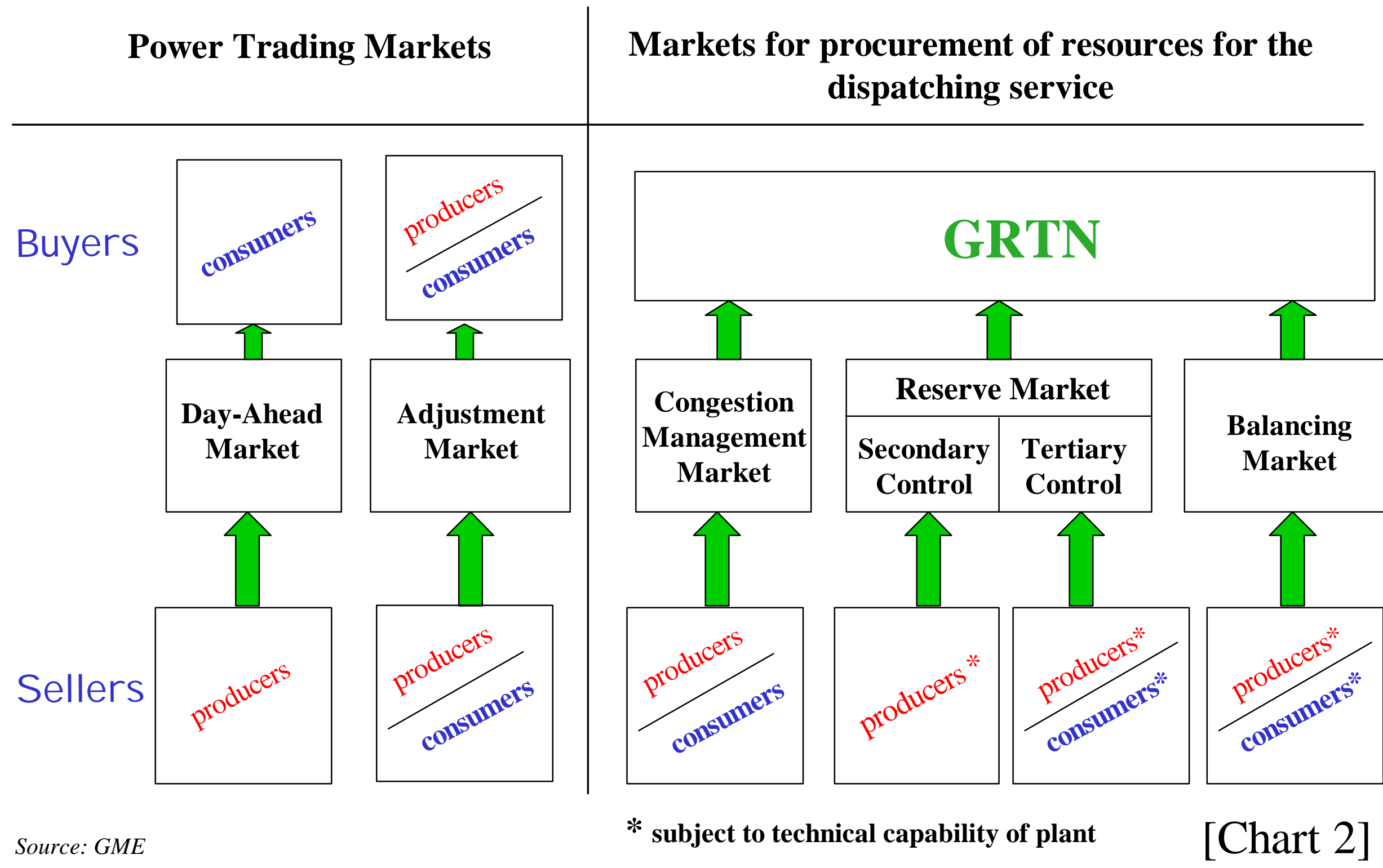




\section{Italy : geographical zones \& transmission constraints [Mw]}

Transmission constraints influence the nature of financial instruments (2003)

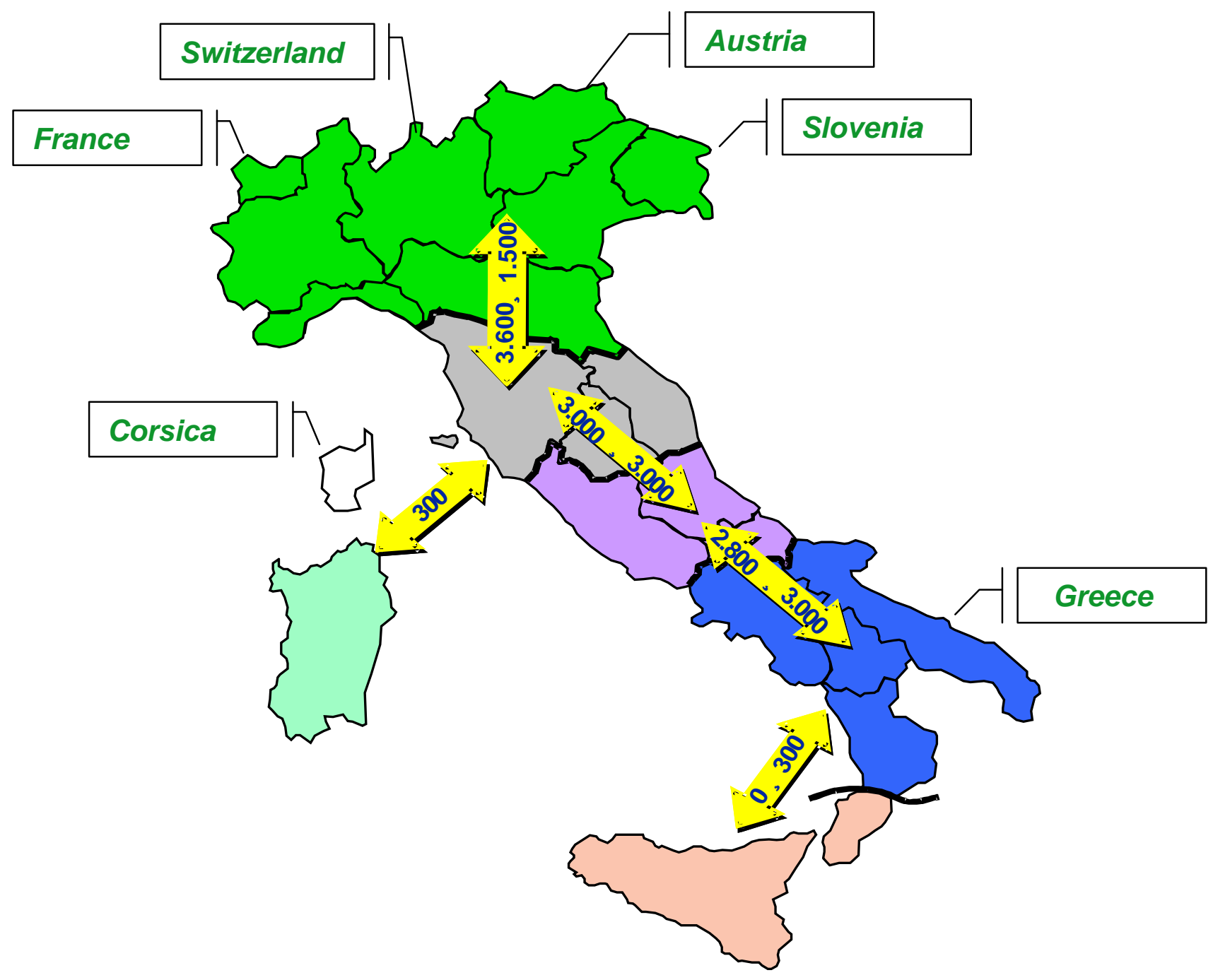

[Chart 3] 


\section{Electricity Balance in Italy. (TWh)}

\begin{tabular}{|c|c|c|c|}
\hline & $\underline{2000}$ & 2001 & \\
\hline Gross Production & 276,6 & 279,6 & \\
\hline Auxiliary Services of Production & $(13,3)$ & $(13,1)$ & \\
\hline Net Production & 263,3 & 266,5 & \\
\hline Imports & 44,8 & 48,9 & \\
\hline Exports & $(0,5)$ & $(0,6)$ & \\
\hline Pumping Consumption & $(\mathbf{9 , 1})$ & $(\mathbf{9 , 4})$ & \\
\hline Energy Supplied & 298,5 & 305,4 & Total Consumption (TWh) \\
\hline Captive Market & 209,4 & 187,3 & France: 410 \\
\hline $\begin{array}{l}\text { Free Market } \\
\quad \text { of which Autoproducer Consumption }\end{array}$ & $\begin{array}{l}\mathbf{6 9 , 9} \\
23,8\end{array}$ & $\begin{array}{l}\mathbf{9 8 , 5} \\
23\end{array}$ & $\begin{array}{l}\text { Germany: } 500 \\
\text { Italy: } \mathbf{2 7 9} \\
\text { Nordic Region: } 360\end{array}$ \\
\hline Total Consumption & 279,3 & 285,8 & Spain: 190 \\
\hline Losses & $(19,1)$ & $(19,6)$ & UK: 340 \\
\hline Energy Supplied & 298,5 & 305,4 & \\
\hline
\end{tabular}




\section{Capacity balance at peak time in 2001. (MW)}

\begin{tabular}{|c|c|}
\hline Installed capacity & 76.400 \\
\hline Available Capacity in Italy & 48.700 \\
\hline Imports & 6.000 \\
\hline Total available capacity & 54.700 \\
\hline Demand peak & 52.000 \\
\hline Reserve margin at the peak & 2.700 \\
\hline$\%$ Capacity reserve at peak time & $5,2 \%$ \\
\hline
\end{tabular}

[Chart 5] 


\section{Italian electricity producers. Year 2001}

Net capacity and Market share

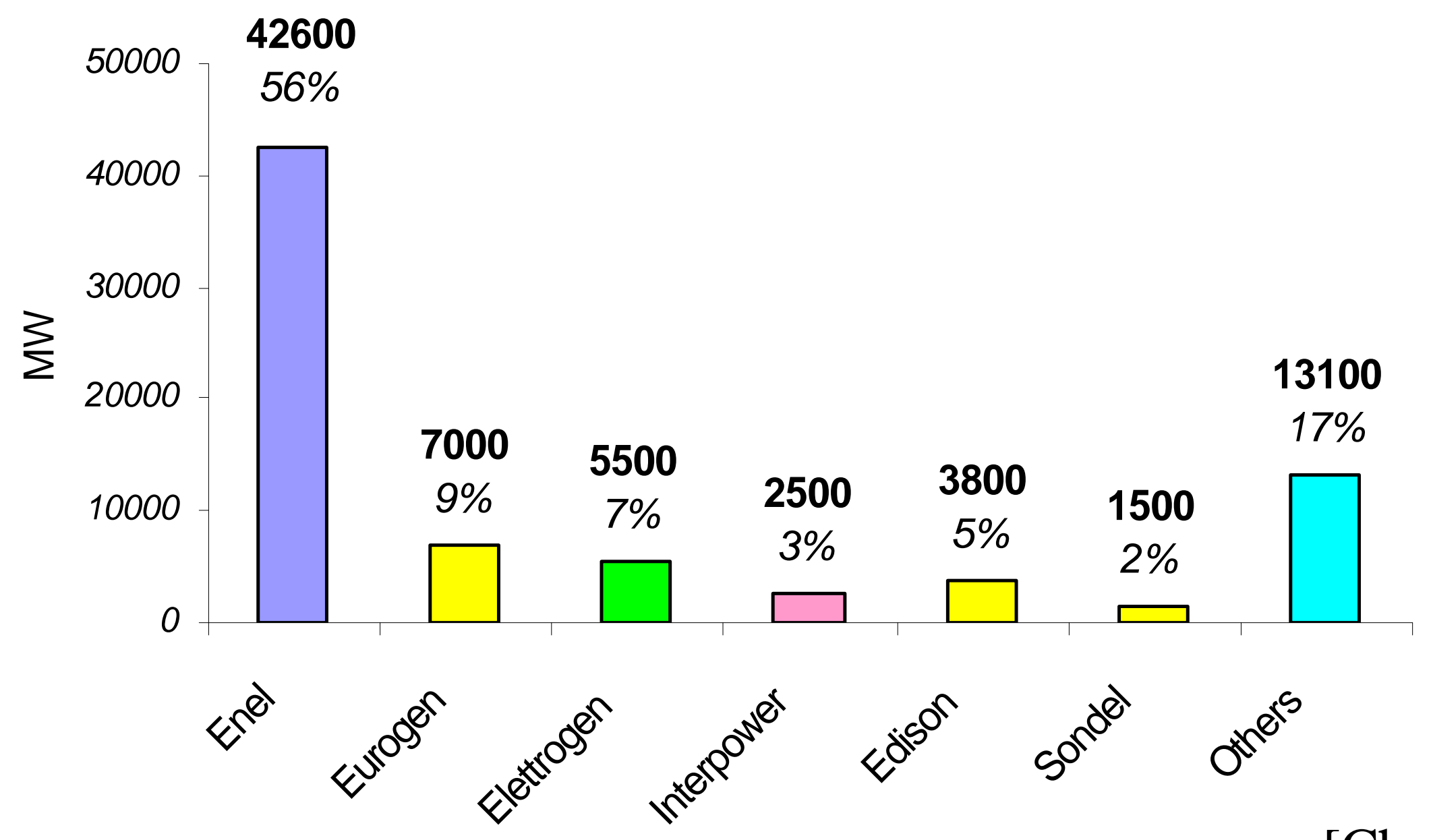

[Chart 6] 


\section{Composition of demand. (TWh)}

\begin{tabular}{|lcc|}
\multicolumn{1}{l}{} & $\mathbf{2 0 0 1}^{(*)}$ & $\mathbf{2 0 0 0}$ \\
\hline $\begin{array}{l}\text { Eligible Market } \\
\text { of which: }\end{array}$ & 98.5 & 69.9 \\
- Own-producer consumption & 23.0 & 23.8 \\
- Import & 27.4 & 22.0 \\
- CIP 6 Production & 34.0 & - \\
- Conventional production & 14.1 & 24.1 \\
\hline & & \\
\hline Captive Market & 194 & 209 \\
\hline & 286 & 279 \\
\hline
\end{tabular}

${ }^{(*)}$ provisional data

[Chart 7] 


\section{Gross electricity generation in major countries in Europe}

by source

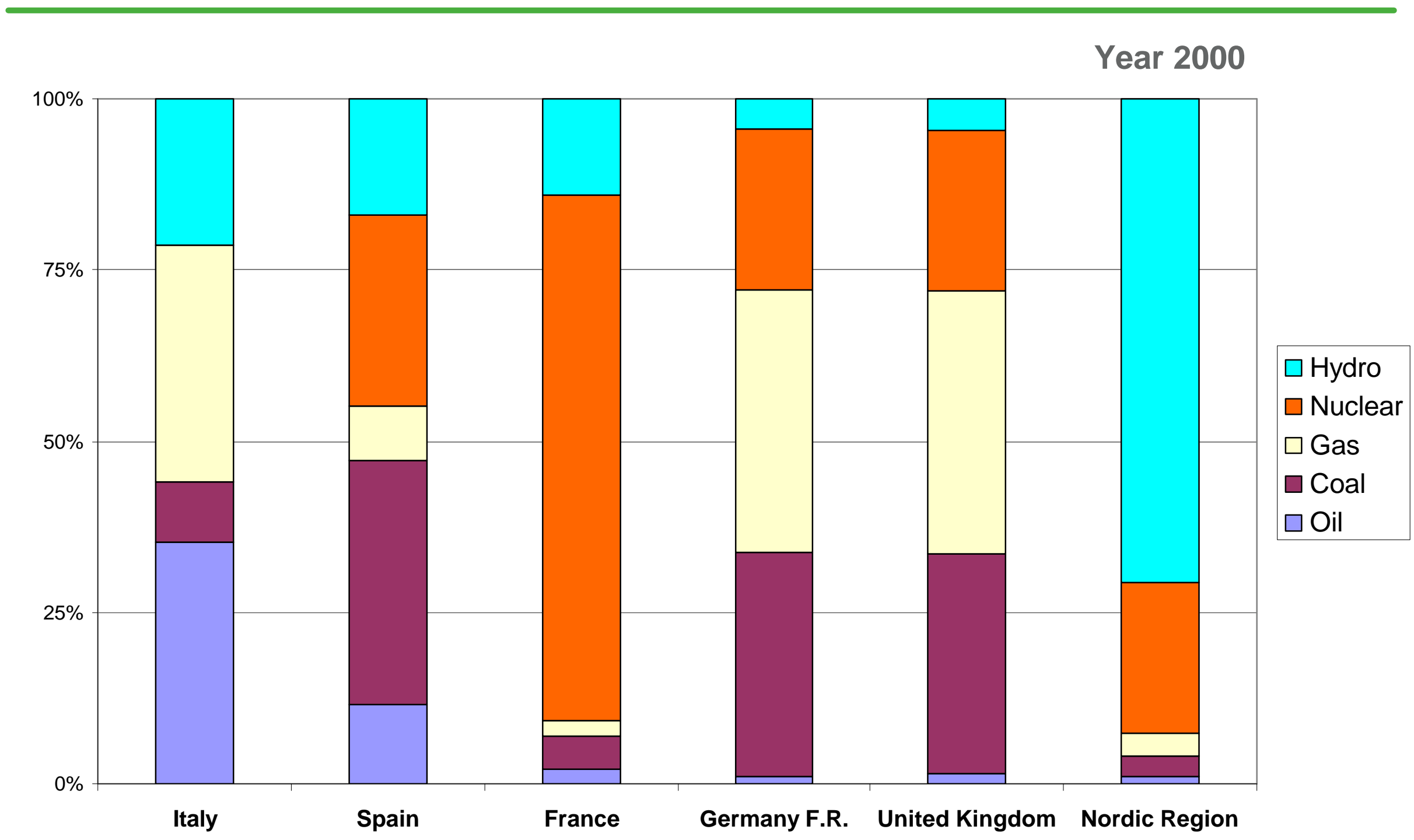

[Chart 8] 


\section{Electricity production in Italy : Fuel cost}

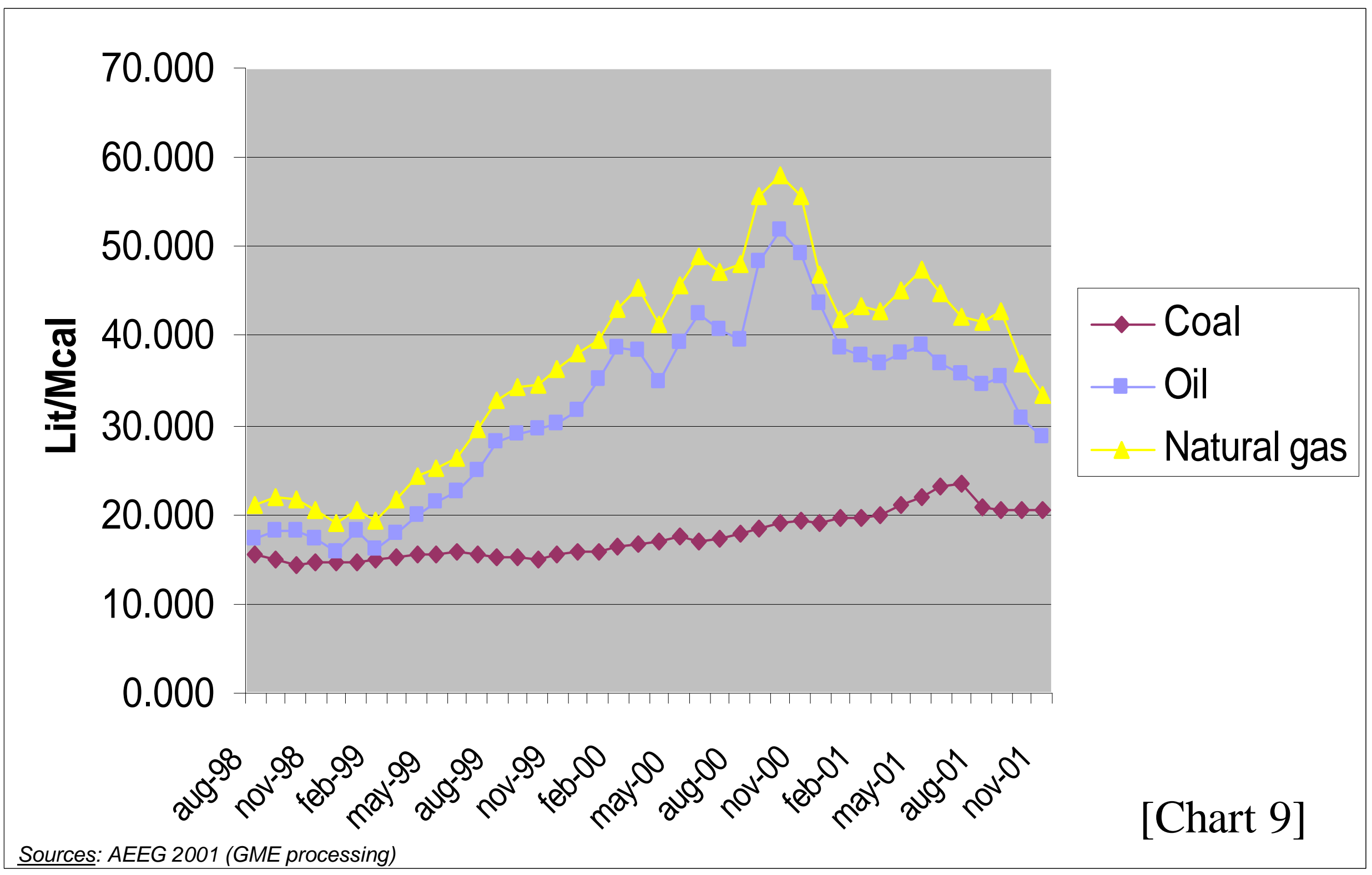




\section{Electricity market players}

\section{Year 2001 producers, traders, consumers}

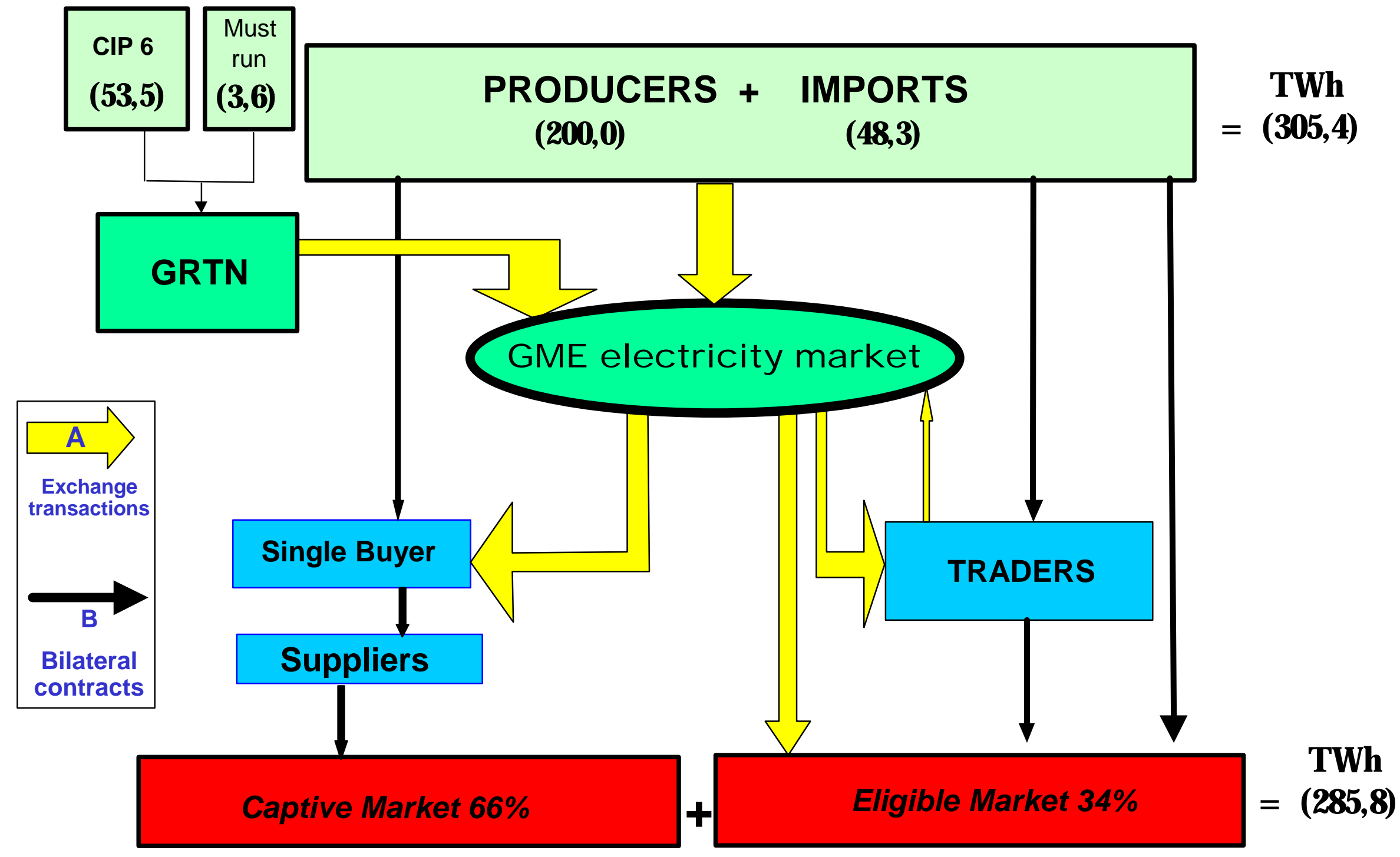




\section{L'esperienza di altri paesi : NORD POOL}

\section{Trend of the electricity physical and financial market?}

- Contracts settled by the Clearing House in 2001: 21,6 mld €

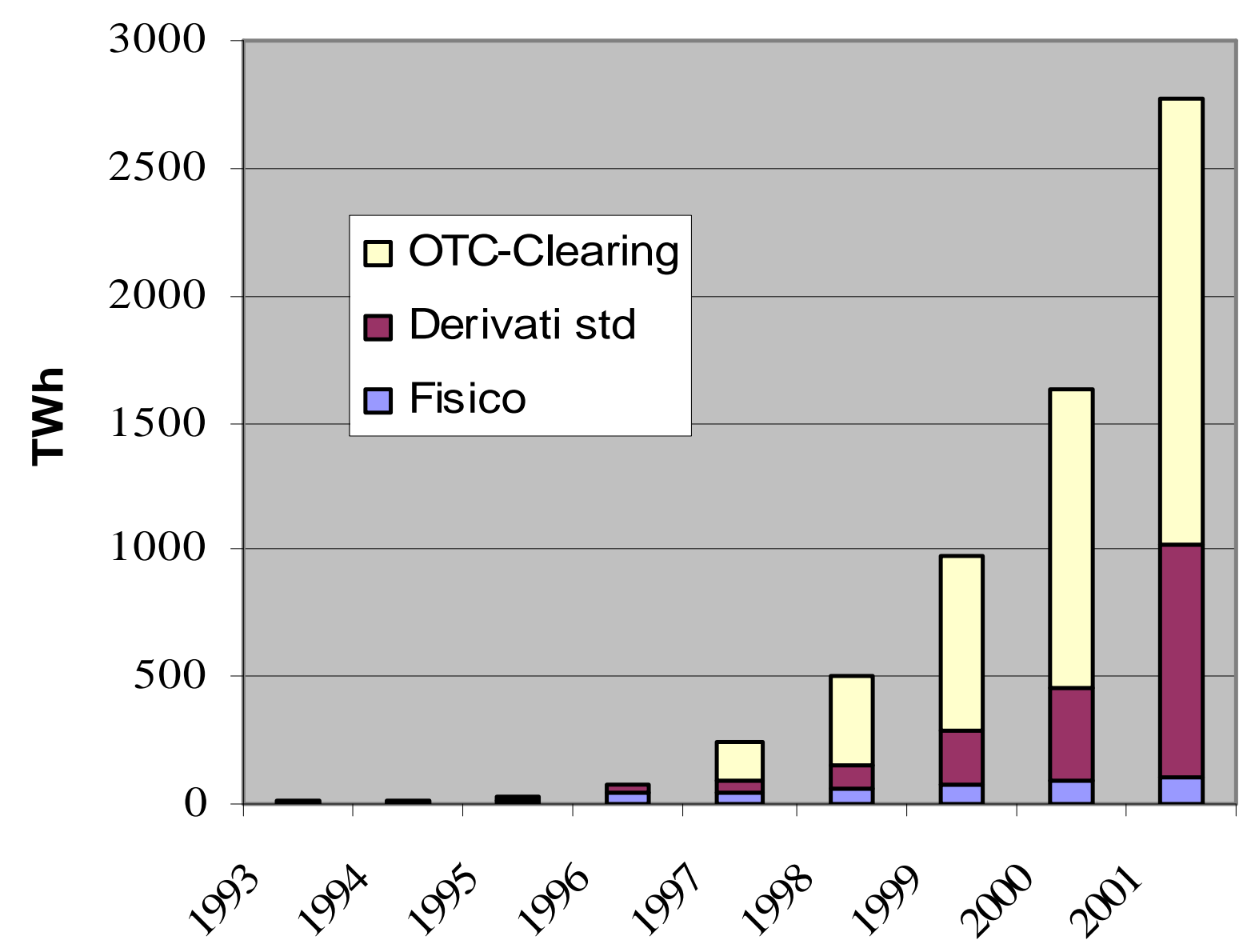

